\title{
The interaction between stimulus variations and age trends in the Poggendorff illusion
}

\author{
JOAN S. GIRGUS \\ Princeton University, Princeton, New Jersey \\ and \\ STANLEY COREN \\ University of British Columbia, Vancouver, British Columbia, Canada
}

\begin{abstract}
Variations in stimulus parameters (distance between the parallels and angle of the transversal) in the Poggendorff illusion were used to explore possible reasons for inconsistencies in the age trends in illusion magnitude found in earlier studies. The data show that the Poggendorff illusion is very sensitive to parametric manipulations and that the age trends are quite different for different configurations of the stimulus array. Systematic sex differences in illusion magnitude were also found.
\end{abstract}

Although the magnitude of most visual-geometric illusions decreases as chronological age of the observer increases, the actual nature of these age-dependent changes in unclear. Both within and between illusion variants, there seem to be differences in the rate of change reported as a function of age. There have even been some instances in which no change has been reported, or in which increases in illusion magnitude have been reported, as age of the observers has increased (for reviews, see Coren \& Girgus, 1978a; Pick \& Pick, 1970). Although several individual-difference-based approaches have been suggested to explain the observed inconsistencies in age trends found for different illusions (e.g., Piaget, 1969; Pollack, 1969), the source of these inconsistencies has been explored only indirectly (e.g., Coren \& Porac, 1978; Girgus, Coren, \& Fraenkel, 1975; Porac \& Coren, 1981).

The Poggendorff illusion, first described by Zöllner in 1860 , generally shows a decrease in illusion magnitude with age (Leibowitz \& Gwozdecki, 1967; Pressey \& Sweeney, 1970; Vurpillot, 1957). However, despite this overall consistency, there seems to be considerable variation among experiments in both the absolute amount of illusion found at any given age and the overall shape of the age trend. For example, Leibowitz and Gwozdecki, Pressey and Sweeney, and Vurpillot all used subjects between the ages of 8.5 and 14.5 years. In this age range, Leibowitz and Gwozdecki found a curvilinear function with the absolute amount of illusion decreasing from 3.3 to $2.6 \mathrm{~cm}$ and most of the decrease occurring between the ages of 8.5 and 10.5 years; Pressey and Sweeney

This research represents the equal and shared contribution of both authors. It was supported in part by grants from the National Science Foundation of the United States (74-18599) and the National Research Council of Canada (A-9783). The authors would like to thank Sandra Boggiano and Rosalind Wu for their assistance in the data collection and analysis. Requests for reprints should be sent to: Joan S. Girgus, Department of Psychology, Princeton University, Princeton, NJ 08544. found a straight line function with the absolute amount of illusion dropping from 4.0 to $2.8 \mathrm{~cm}$; and Vurpillot found a slightly curvilinear function with a shallower slope than those found in the other two experiments and the absolute amount of illusion decreasing from 1.7 to $1.5 \mathrm{~cm}$.

One way to think about the heterogeneity of these results emerges from reports on age trends in the Ebbinghaus and Müller-Lyer illusions (Coren \& Porac, 1978; Girgus, Coren, \& Fraenkel, 1975; Porac \& Coren, 1981), in which different age trends were found within the same illusion, depending upon the specific variant of the illusion tested. In each case, the differences in the age trends probably resulted from the fact that most illusions are the result of several mechanisms acting in concert to produce the final distortion (Coren \& Girgus, 1973, 1974, 1978a, 1978b; Coren, Girgus, Ehrlichman, \& Hakstian, 1976; Girgus, Coren, Durant, \& Porac, 1975). The differences in illusion magnitude among the variants of a given illusion can thus be seen as resulting from variations in the influence of each of the mechanisms that contribute to that illusion. If different mechanisms have different age trends, then one would expect to find that age trends differ among variants of any given illusion.

It is well known that the magnitude of the Poggendorff illusion is sensitive to variations both in the angle at which the transversal meets the parallels and in the distance between the parallels (Cameron \& Steele, 1905; Coren \& Girgus, 1978a; Krantz \& Weintraub, 1973; Wagner, 1969; Weintraub \& Krantz, 1971). In general, the magnitude of the illusion increases as angle size decreases and distance between the parallels increases. Explanations for the angle-size effect have usually focused on the optical or neural interactions in the visual system, whereas explanations for the effect of distance between the parallels have tended to focus more on cognitive-judgmental strategies or abilities (e.g., Coren \& Girgus, 1978a). However, there have been suggestions that the effect of angle size 
has a cognitive-judgmental basis as well (e.g., Krantz \& Weintraub, 1973; Weintraub \& Krantz, 1971), and that the effect of distance between the parallels has an opticalneural basis (e.g., Quina-Holland, 1977), at least for figures subtending only a few degrees of visual arc.

Age trends in illusion strength have also usually been ascribed either to structural changes that affect the optical or neural interactions in the visual system as the individual matures, or to changes in cognitive-judgmental strategies or abilities. For example, Pollack (1978) argued that, because the amount of lateral inhibition on the retina declines with age, the magnitude of any illusion that depends on such neural interactions in the retina will also decline with age (e.g., Pollack, 1969). Some support for this view is provided by Coren and Girgus (1976) and Girgus, Coren, and Fraenkel (1975), who, working with the Müller-Lyer illusion, were able to demonstrate that the usually obtained age trend was greatly weakened when the standard configuration was varied to eliminate the possibility of lateral inhibitory interactions. Piaget (1969), on the other hand, proposed a cognitive-judgmental explanation for age changes in illusion magnitude. According to his theory, observation of the stimulus array involves a series of shifts of attentional focus, which he called centrations. He suggested that any target that receives many centrations will tend to be overestimated in size. Accurate perception is possible when observers make comparisons, called couplings, between elements of the array. Experimental evidence for the importance of attentional factors on illusion magnitude has come from other sources (e.g., Coren \& Porac, 1983). Since there are age changes in the distribution of attention (such as increases in the number of couplings and decreases in the number of centrations), Piaget's theory can predict systematic changes in illusion magnitude as a function of age.

If appropriate sets of illusion variants are selected, it ought to be possible to discriminate among the various theories that try to account for age trends in perception of the Poggendorff illusion. For example, if age changes lateral inhibitory mechanisms, then different age trends might be expected as a function of changes in transversal angle, whereas, if cognitive-judgmental changes are responsible for the age trends, changes in separation of parallels might be expected to produce the greatest variation in age trends in illusion magnitude. Unfortunately, each of the three developmental studies on the Poggendorff illusion reported to date (Leibowitz \& Gwozdecki, 1967; Pressey \& Sweeney, 1970; Vurpillot, 1957) limited its measurements to a single configuration; hence, such comparisons of age trend as a function of configuration cannot be made. To directly assess how age trends vary for particular illusion variants (presumably due to the differential contribution of the various illusion mechanisms to each configuration), it is necessary to parametrically vary the major parameters within a given illusion array, as well as the age of the subjects tested. The present study was designed to accomplish this systematic variation.

\section{METHOD}

\section{Subjects}

Twenty first graders (mean age 6.2 years), 20 third graders (mean age 8.3 years), 20 fifth graders (mean age 10.4 years), and 20 college undergraduates (mean age 20.3 years) served as subjects. The elementary-school subjects were drawn randomly from among the students at a public school and the adult subjects were volunteers from a public college in New York City. Half the subjects in each age group were male and half were female.

\section{Stimuli and Apparatus}

The basic stimulus configuration is shown in Figure 1. There were nine actual stimuli, representing every possible combination of three angles of the transversal with the parallels $\left(30^{\circ}, 45^{\circ}\right.$, and $\left.60^{\circ}\right)$ and three distances between the parallels $(2 \mathrm{~cm}, 4 \mathrm{~cm}$, and $6 \mathrm{~cm})$. All nine stimuli were drawn with 1-mm lines; in each stimulus, the parallels were $22 \mathrm{~cm}$ long and the lower half of the transversal was $4 \mathrm{~cm}$ long. Each stimulus was drawn in the center of a $21.5 \times 28 \mathrm{~cm}$ ditto master, resulting in a final set of printed stimuli consisting of dark purple lines on a white background. At the distance used, the stimuli subtended $27^{\circ}$ of visual angle in the vertical dimension and from $6^{\circ}$ to $17^{\circ}$ in the horizontal dimension.

\section{Procedure}

Because of the age of the younger subjects, special care was taken to ensure that the nature of the judgment required was clearly understood. In instructing each subject, the experimenter first displayed a white cardboard rectangle and a piece of stiff wire. Then, holding the cardboard rectangle upright, the experimenter placed the wire behind the rectangle and at an angle to it so that the wire formed the lower segment of the transversal and the rectangle and wire together looked like Figure 1. The experimenter then moved the wire diagonally so that it emerged at the other side of the cardboard rectangle and made a standard Poggendorff configuration. The experimenter then withdrew the wire so that, again, only half of the transversal was visible, and asked the subject to point to the place on the cardboard rectangle at which the subject thought the wire would come out if the experimenter pushed it through again.

The experimenter next showed the subject a sample experimental stimulus and explained that it was a drawing of the cardboard rectangle with the wire pushed partway behind it. The subject was asked to make a penciled $X$ on the right-hand parallel at the point at which the wire would reappear if it were pushed all the way through. This is a variation of a technique that has been shown to provide stable measures of the Poggendorff illusion with enough

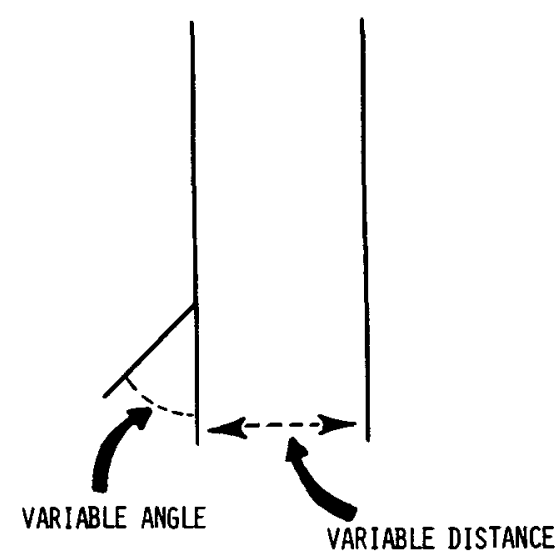

Figure 1. The Pogendorf configuration used in this experiment. 
sensitivity to register the effects of standard manipulations of the stimulus parameters (e.g., Coren \& Porac, 1979). The subject was cautioned to place the intersection of the lines of the $X$ on the righthand parallel (if a subject failed to do so precisely, a horizontal line was later drawn from the intersection of the lines of the $X$ to the right-hand parallel, and the point of intersection of this horizontal line with the parallel was used for measurement purposes). The subjects were generally accurate about placing the intersection of the lines of the $X$ on the parallel, and no subject made any mark with the point of intersection displaced more than $3 \mathrm{~mm}$ horizontally from the right-hand vertical.

Each subject was asked to make a judgment on all nine stimulus configurations, which were presented in random order.

\section{RESULTS AND DISCUSSION}

The distance between each subject's penciled $X$ and the actual point of continuation of the transversal was calculated for each judgment. An overall analysis of variance was then conducted on these measures, with the maineffect variables age $\times$ sex $\times$ distance between the parallels $x$ angle of the transversal. The outcomes of this analysis are discussed below in relation to the substantive issues that they address.

\section{Stimulus Variations and Illusion Magnitude}

First, let us consider the effects of the stimulus manipulations on illusion magnitude, independent of the age variable. Figure 2 illustrates how illusion magnitude varies as a function of variation in the angle of the transversal and the separation between the parallels (data collapsed across all age groups). As can be seen from the figure, as the angle becomes more acute, the magnitude of the illusion increases; this main effect is statistically significant $[F(2,144)=849.51, p<.01]$. Similarly, increas- ing the separation between the parallels increases the size of the distortion, and this is also statistically significant $[F(2,144)=767.52, p<.01]$. In general, these effects appear to be additive in nature; however, as is seen from the divergence of the functions, there is also an interaction between angle and separation that is significant $[F(4,288)=196.24, p<.01]$. These data confirm the frequently reported findings that the magnitude of the Poggendorff varies with variations in these parameters (Cameron \& Steele, 1905; Coren \& Girgus, 1978a; Krantz \& Weintraub, 1973; Wagner, 1969; Weintraub \& Krantz, 1971), and thus demonstrate that the measurement technique used here is sufficiently sensitive to pick up the most frequently reported variations in illusion magnitude.

\section{Effect of Age on Illusion Magnitude}

The data demonstrate a clear trend toward a decrease in illusion magnitude with increasing chronological age of the subjects. Collapsing the data across all illusion configurations, we find that, for the 6-year-old group, illusion magnitude is $24.3 \mathrm{~mm}$, which diminishes to $19.7 \mathrm{~mm}$ in the 8-year-old group, $17.0 \mathrm{~mm}$ in the 10 -year-old group, and $12.3 \mathrm{~mm}$ in the 20-year-old group. This decrease is statistically significant $[F(3,76)=6.43$, $p<.01]$. The actually obtained age trends, however, differ depending upon the particular configuration tested. Figure 3 illustrates the effect on the age trend of variation of the transversal angle. As can be seen, the general tendency for illusion magnitude to decrease is clearly present; however, the rate of decrease is highly dependent on the angle of the transversal. The $30^{\circ}$ transversal, which produces the greatest illusion magnitude, also produces the most marked age trend. Although the $60^{\circ}$ transversal produces a statistically significant illusion for

\section{ANGLE AND SEPARATION EFFECTS}

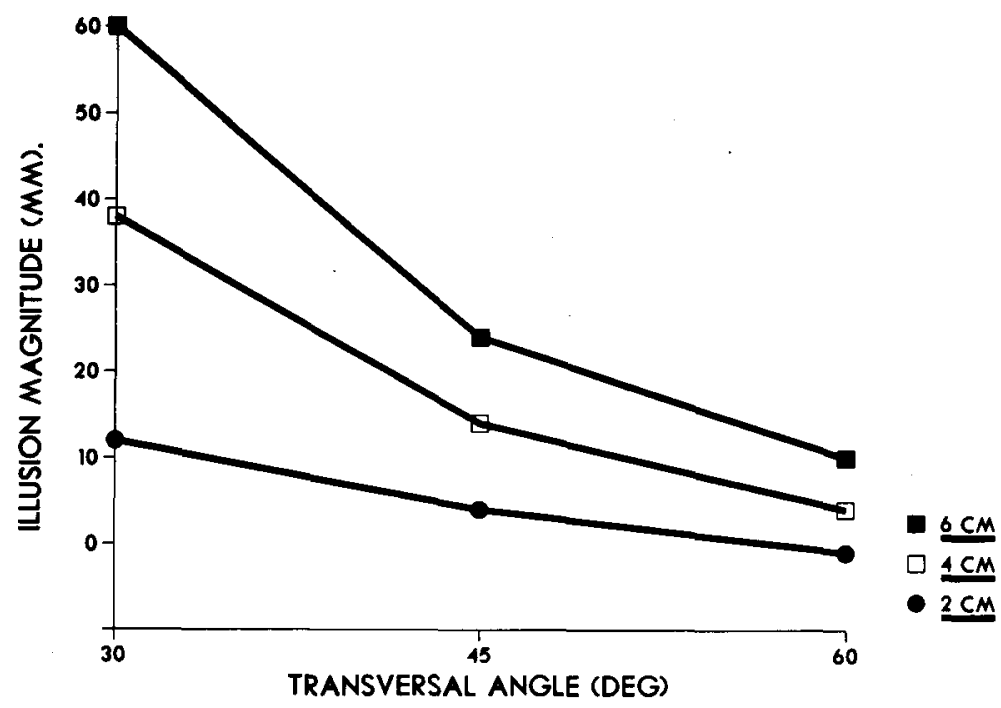

Figure 2. The effect of distance between the parallels and angle of the transversal on Poggendorff illusion magnitude. 


\section{EFFECT OF TRANSVERSAL ANGLE}

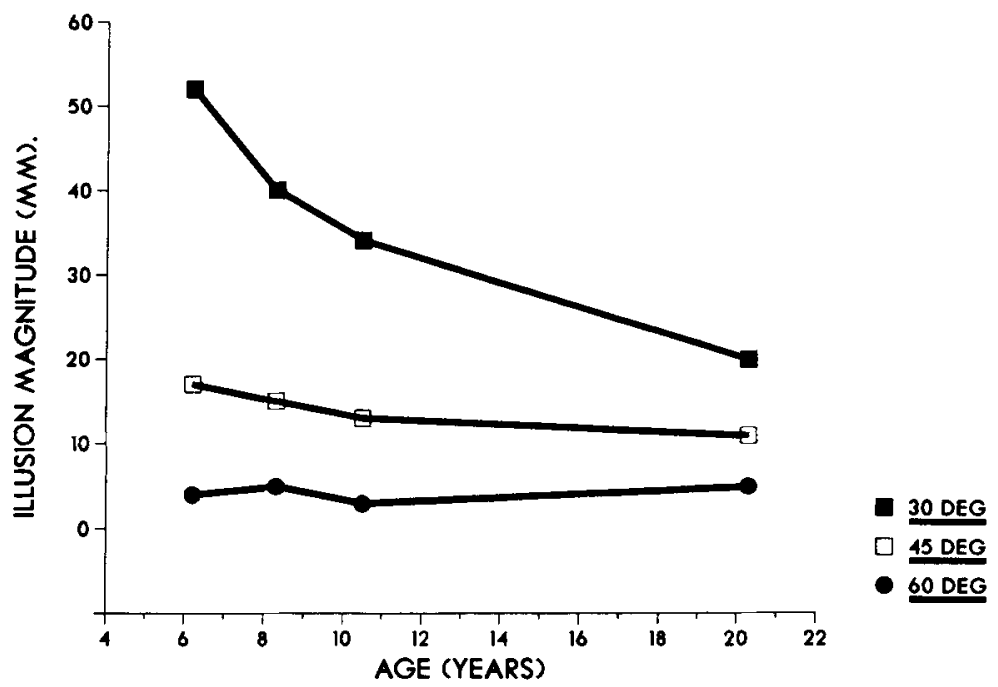

Figure 3. Age trends in Poggendorff illusion magnitude as a function of angle of the transversal.

each of the age groups tested $[t(19)=2.18,2.31,2.10$, and 2.16 for the 6-year-olds, 8-year-olds, 10-year-olds, and 20-year-olds, respectively; $p<.05$ for all], virtually no age trend appears for this configuration at all. The fact that the strength of the age trend varies as a function of the transversal angle manifests itself statistically as a significant interaction between age and the angle of the transversal $[F(6,144)=34.73, p<.01]$.

Figure 4 shows an interaction between variations of the separation between the parallels and age. Here we find an indication that the largest separation $(6 \mathrm{~cm})$ produces the most marked reduction of the illusion with age. For the smallest separation ( $2 \mathrm{~cm})$, although the illusion magnitude is significant for all age groups $[t(19)=2.36,2.27$, 2.10 , and 2.18 for the 6-year-olds, 8-year-olds, 10 -yearolds, and 20-year-olds, respectively; $p<.05$ for all], only the most minimal age trend is visible. The apparent interaction is statistically significant $[F(6,144)=15.70$, $p<.01$ ]. In one important respect, these results duplicate those found for variations in the transversal; namely, the configuration that produces the most marked illusion also produces the most marked age trend.

In Figure 5, each combination of transversal angle and distance between the parallels is considered separately.

\section{EFFECT OF PARALLEL SEPARATION}

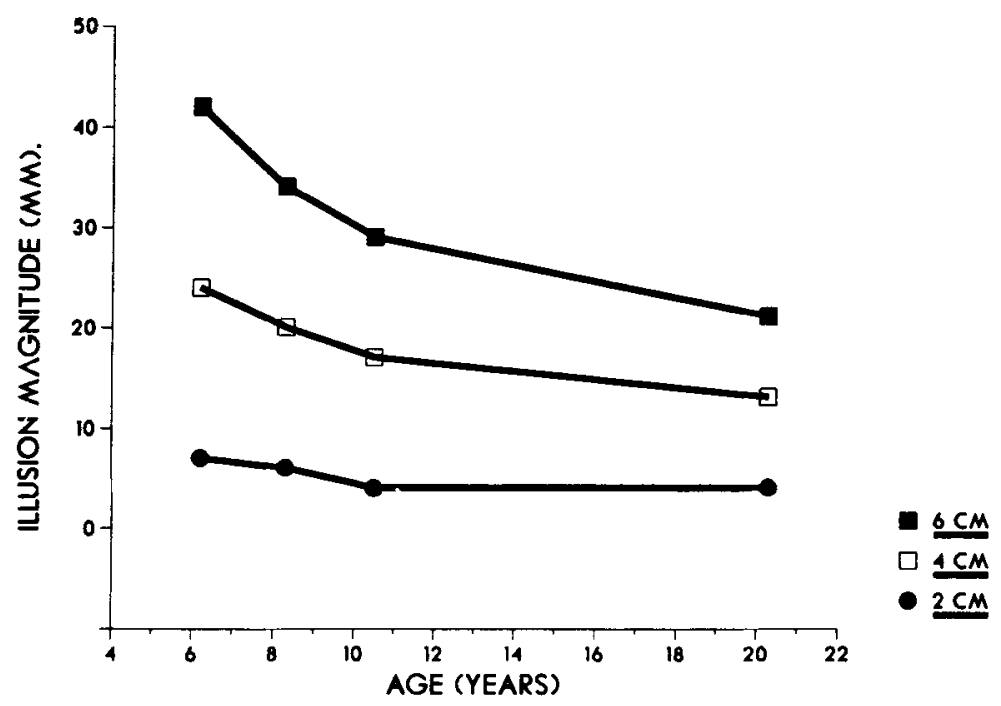

Figure 4. Age trends in Poggendorf illusion magnitude as a function of distance between the parallels. 


\section{AGE BY ANGLE AND SEPARATION}

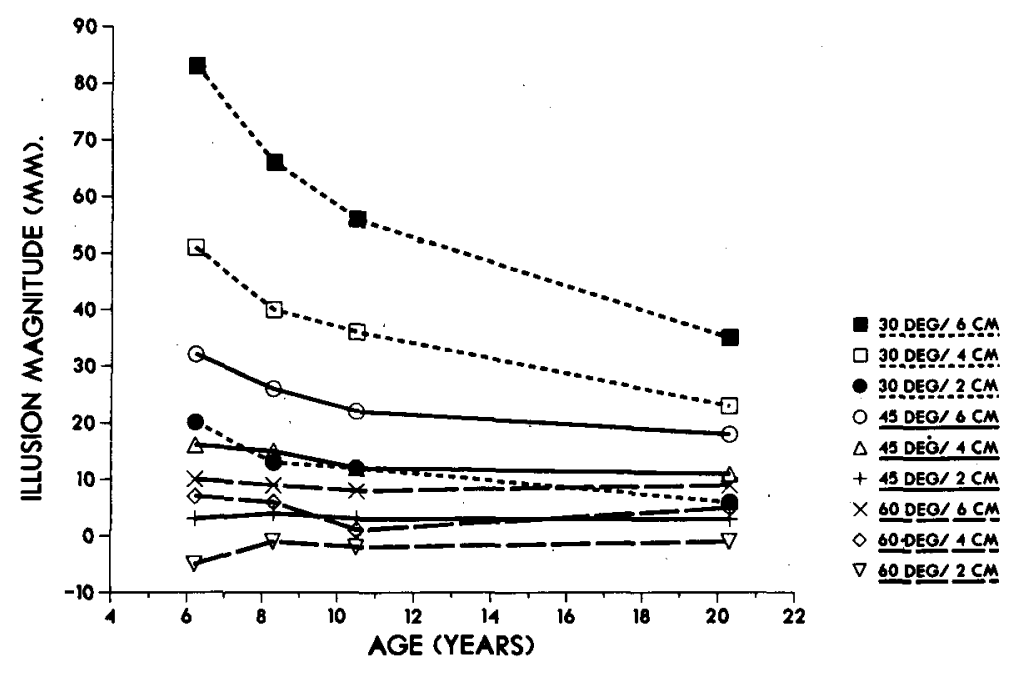

Figure 5. Age trends in Poggendorf illusion magnitude as a function of angle of the transversal and distance between the parallels.

The weaker the illusion, in general, the less pronounced the age trend. Thus, there are age-related decreases in the illusion magnitude for angle/separation combinations of $30 / 6,30 / 4,30 / 2,45 / 6$, and $45 / 4$, but no age trends at angle/distance combinations of $45 / 2,60 / 6,60 / 4$, and $60 / 2$. Furthermore, even within those stimulus configurations in which an age trend is manifested, the ordering seems to be predicted by the presence of stimulus parameters that produce the greatest illusion magnitude. The size of the age decrease is greatest for the angle/distance combination of 30/6, next largest for 30/4, next largest for $45 / 6$, and least for $45 / 4$ and $30 / 2$. As might be expected from these considerations, this pattern of data results in a significant three-way interaction between age, transversal angle, and separation between the parallels $[F(12,288)=5.89, p<.01]$.

In summary, these results show that age trends in illusion magnitude are responsive to stimulus variations, which presumably reflect variations in the contributions of illusion-producing mechanisms. The general pattern is that the greater the illusion magnitude, the more pronounced the age-related decrease. This result may well explain the apparent disparities in the literature about the nature of age trends in the Poggendorff illusion. In any study that employs a sufficiently strong variant of the illusion (e.g., a very acute angle on the transversal and wide separation between the parallels), one may expect to find a pronounced and rapid diminution of illusion magnitude with increasing chronological age. A study that employs a weaker, albeit still significant, variant of the illusion will probably show little or no age trend. Thus the variability of the developmental changes in illusion strength reflects the interaction between illusion magnitude and age effects.

\section{Sex Differences in Illusion Magnitude}

Equal numbers of males and females were included in these samples in order to allow an assessment of sex differences in response to the illusion. There appear to be good reasons to expect sex differences in illusion magnitude. For instance, Coren and Porac (1985) showed that, for a number of different illusion configurations, illusion magnitude is inversely related to certain spatial skills. Since, in general, females show lower levels of performance in these types of spatial skills, one might expect to find systematic sex differences in illusions, with females showing greater illusion magnitude. It is therefore somewhat surprising that few studies have found such differences. For instance, Porac, Coren, Girgus, and Verde (1979) tested 221 subjects on 23 illusion variants and found virtually no significant sex differences.

For the Poggendorff illusion, the data on sex differences have been mixed. Vurpillot (1957) found no sex differences in a study that included subjects between the ages of 5 and 40 years, nor did Leibowitz and Gwozdecki (1967) find any in a study with subjects ranging in age from 5 to 80 years. Porac et al. (1979) found a slightly greater illusion magnitude for males than for females. On the other hand, Pressey and Sweeney (1970) found a greater illusion magnitude for females, for subjects between the ages of 8 and 15 years.

In analyzing the data from this study, we find that, overall, females seem to be more susceptible to the Poggendorff illusion than are males, with composite illusion magnitudes (averaged across all stimulus variants) of $21.0 \mathrm{~mm}$ for females and $15.7 \mathrm{~mm}$ for males. This difference is significant $[F(1,72)=5.72, p<.05]$. Further analysis of these results suggests an explanation for the apparent variability in former reports of sex differences in the Pog- 
SEX BY ANGLE AND SEPARATION

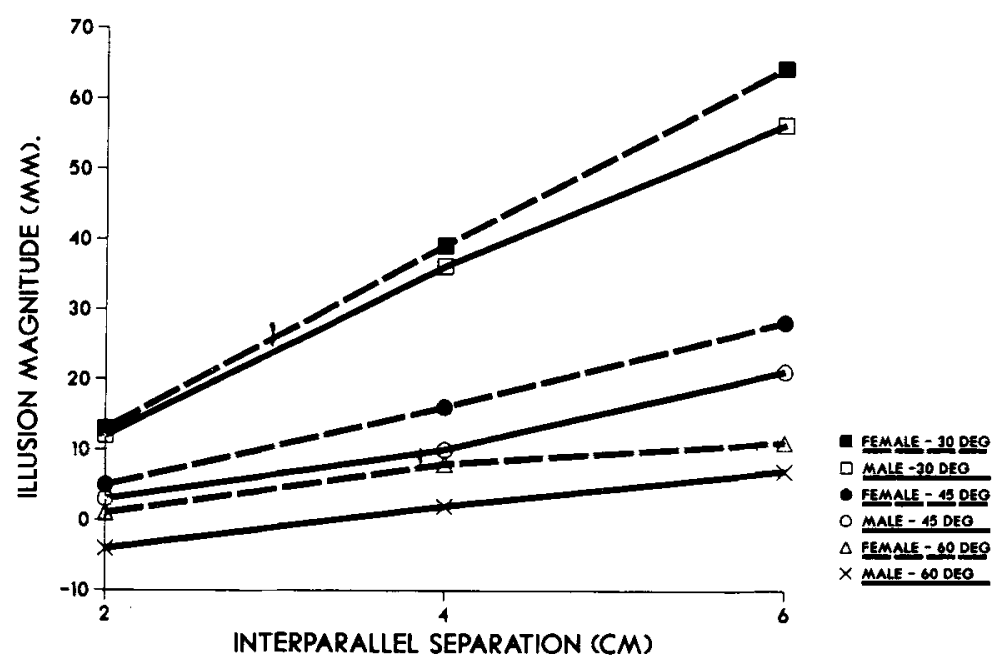

Figure 6. Sex differences in Poggendorff illusion magnitude as a function of distance between the parallels and angle of the transversal. gendorff illusion that is analogous to the explanation suggested for the diversity in the reports of age trends in the illusion. Namely, there appears to be an interaction between the magnitude of the illusion and the size of the sex differences obtained. This is clearly shown in Figure 6, which plots the magnitude of the illusion, for each sex separately, as a function of transversal angle and separation between the parallels.

As Figure 6 indicates, at each transversal and separation combination, females show greater illusion magnitude. The interesting aspect of this figure is the apparent interaction, in which the magnitude of the sex differences is considerably smaller for the smaller interparallel distances. At a 2-cm separation between the parallels, females show a mean illusion that is $4 \mathrm{~mm}$ greater than that of males. This difference is nearly doubled (rising to $7 \mathrm{~mm}$ ) for the 6-mm separation illusion configuration. This effect manifests itself in a significant sex $\times$ separation interaction $[F(2,144)=4.39, p<.05]$, and also carries over to produce a significant three-way interaction of sex $\times$ separation $\times$ angle size $[F(4,288)=2.65$, $p<.011$.

As in the case of age trends, the strength of the sex differences seems to covary with the size of the illusion. In strong variants of the illusion, particularly in variants in which there is large interparallel separation, sex differences are amplified. Thus one might hypothesize that experiments that have reported an absence of sex-related differences have used a nonoptimal illusion configuration.

\section{GENERAL DISCUSSION}

Although the data presented above cannot explain why there is an age-related decrease in the strength of the Poggendorff illusion, they do help to clarify why there have been so many inconsistencies in reports of age trends or sex differences in the perception of this illusion. It seems that age trends, like illusion magnitude, are highly sensitive to variations in the angle of the transversal and the separation between the parallels. In general, Poggendorff configurations that contain more acute angles at the transversal or wider separation between the parallels produce the most pronounced age trends. Since these combinations of elements also lead to greater illusion strength in general, it is unclear whether it is the specific pattern of elements employed or whether it is the original illusion magnitude that is the primary determinant of the strength of the age trend.

It is certainly possible to speculate about some of the specific pattern elements in the Poggendorff illusion, and the ways in which these elements may interact with developmental changes to cause the age trends that are observed for some configurations but not others. For example, a reduction in angle size would be expected to lead to an increase in the contribution of lateral inhibitory factors that are presumed to contribute to the illusion (see Coren \& Girgus, 1978a, 1978b). Insofar as the amount of lateral inhibition on the retina declines with age (Pollack, 1978), we might thus expect illusion configurations with more acute angles to show greater age effects than illusions with more obtuse angles. On the other hand, changes in illusion magnitude with increasing separation of the parallels are probably due more to cognitivejudgmental factors, such as the distribution of attention over the figure (Coren \& Porac, 1983; Pressey \& Murray, 1976), temporal or spatial comparison processes (Girgus \& Coren, 1982; Piaget, 1969), or information extracted to guide eye movements (Coren, 1986). Hence, age trends observed in configurations with wider separation may be due to developmental changes in these processes. Alternatively, it may be illusion magnitude per se that is important in determining the presence of age 
changes, because, despite a significant amount of illusion at all ages, it is the weaker configurations that fail to show developmental changes.

A similar pattern holds for sex differences, with the most pronounced gender effects appearing in the illusion configurations that produce the largest distortions. However, in the sex-difference data presented above, separation between the parallels seems to be more important than angle of the transversal. This makes it reasonable to speculate that the sex-difference data reflect attentional or cognitive-judgmental strategy differences between males and females, rather than differences in lateral neural interactions.

At a minimum, the need for caution clearly emerges from these data. Researchers should be aware that the absence of a manifest age trend (or sex difference) for a given illusion configuration does not necessarily mean that such a trend will not be found for other (presumably stronger) variants of the same illusion array. The converse, of course, is also true: age trends in one form of an illusion do not always predict age trends in all other variants. The clear methodological implication of these results for developmental researchers is that multiple variants of a given illusion should be used at each age. This will give a clearer indication of whether age trends are apt to appear, and perhaps indicate some of the relevant stimulus parameters that affect them. If, due to limitations of time or money, it is not possible to use multiple variants, researchers should endeavor to use the variant of the illusion that produces the maximum magnitude of distortion.

\section{REFERENCES}

Cameron, E. H., \& Steele, W. M. (1905). The Poggendorff illusion. Psychological Review, 11, 83-111.

COREN, S. (1986). An efferent component in the visual perception of direction and extent. Psychological Review, 93, 391-410.

Coren, S., \& Girgus, J. S. (1973). Visual spacial illusions: Many explanations. Science, 179, 503-504.

Coren, S., \& GrRgus, J. S. (1974). Transfer of illusion decrement as a function of perceived similarity. Journal of Experimental Psychology, 102, 881-887.

Coren, S., \& Girgus, J. S. (1976). Perceptual development: A distorted view. In K. F. Riegel \& J. A. Meacham (Eds.), The developing individual in a changing world: Vol. 1 . Historical and cultural issues (pp. 244-254). The Hague: Mouton.

COREN, S., \& GIRGUS, J. S. (1978a). Seeing is deceiving: The psychology of visual illusions. Hillsdale, NJ: Erlbaum.

COREN, S., Girgus, J. S. (1978b). Visual illusions. In H. Leibowitz \& H.-L. Teuber (Eds.), Handbook of sensory physiology: Voll. 8. Perception (pp. 549-568). Berlin: Springer-Verlag.

Coren, S., Girgus, J. S., Ehruchman, H., \&akstian, A. R. (1976). An empirical taxonomy of visual illusions. Perception \& Psychophysics, 20, 129-137.
Coren, S., * Porac, C. (1978). A new analysis of life-span age trends in visual illusions. Developmental Psychology, 14, 193-194.

CoREN, S., \& PORAC, C. (1979). Techniques for the measurement of the Poggendorff and Zoellner illusions in large group situations. Bulletin of the Psychonomic Society, 13, 219-222.

Coren, S., \& Porac, C. (1983). The creation and reversal of the Mueller-Lyer illusion through attentional manipulation. Perception, 12, 49-54.

Coren, S., Porac, C. (1985). Individual differences in visualgeometric illusions. In J. L. McGaugh (Ed.), Contemporary psychology: Biological processes and theoretical issues (pp. 395-398). Amsterdam: Elsevier Science Publishers (North-Holland).

GIRGUS, J. S., \& CoREN, S. (1982). Assimilation and contrast illusions: Differences in plasticity. Perception \& Psychophysics, 32, 555-561.

Grrgus, J. S., Coren, S., Durant, M., \& Porac, C. (1975). The assessment of components involved in illusion formation using a longterm decrement procedure. Perception \& Psychophysics, 18, 144-148.

Girgus, J. S., Coren, S., * Fraenkel, R. (1975). Levels of perceptual processing in the development of visual illusions. Developmental Psychology, 11, 268-273.

Krantz, D. H., Weintraub, D. J. (1973). Factors affecting perceived orientation of the Poggendorff transversal. Perception \& Psychophysics, 14, 511-517.

LeIBowitz, H. W., GwozDECKI, J. (1967). The magnitude of the Poggendorff illusion as a function of age. Child Development, 38, 573-580.

PIAGET, J. (1969). The mechanisms of perception (G. N. Seagrine, Trans.). New York: Basic Books.

Pick, H. L., JR., \& Pick, A. D. (1970). Sensory and perceptual development. In P. H. Mussen (Ed.), Carmichael's manual of child psychology (pp. 773-848). New York: Wiley.

PollAck, R. H. (1969). Some implications of ontogenetic changes in perception. In J. Flavell \& D. Elkind (Eds.), Studies in cognitive development: Essays in honor of Jean Piaget. New York: Oxford University Press.

Pollack, R. H. (1978). A theoretical note on the aging of the visual system. Perception \& Psychophysics, 23, 94-95.

PorAc, C., \& CorEN, S. (1981). Life-span age trends in the perception of the Mueller-Lyer: Additional evidence for the existence of two illusions. Canadian Journal of Psychology, 35, 58-62.

Porac, C., Corre, S., Girgus, J. S., a Verde, M. (1979). Visualgeometric illusions: Uni-sexed phenomena. Perception, 8, 401-412.

PREsseY, A. W., MURRAY, R. (1976). Further developments in the assimilation theory of geometric illusions: The adjacency principle. Perception \& Psychophysics, 19, 536-544.

Pressey, A. W., Sweeney, O. (1970). Age changes in the Poggendorff illusion as measured by a method of reproduction. Psychonomic Science, 19, 99-100.

Quina-Holland, K. (1977). Spatial distortions within the Poggendorff figure and its variants: A parametric analysis. Perception \& Psychophysics, 21, 118-124.

VurPILLOT, E. (1957). L'influence de la signification du materiel su l'illusion de Poggendorff. Année Psychologie, 57, 339-357.

WAGNER, H. L. (1969). Simultaneous and successive contour displacements. Unpublished doctoral thesis, University of Wales.

Weintraub, D. J., \& Krantz, D. H. (1971). The Poggendorff illusion: Amputations, rotations and other perturbations. Perception \& Psychophysics, 10, 257-264.

(Manuscript received January 21, 1986; revision accepted for publication October 10, 1986.) 